\title{
Violencia institucional y participación política juvenil: la experiencia de la Marcha de la Gorra (Córdoba)
}

\author{
Mariana Jesica Lerchundi ${ }^{1}$ \\ María del Rocío Alonso ${ }^{2}$
}

Fecha de recepción: 18 de marzo de 2019

Fecha de aprobación: 6 de mayo de 2019

Fecha de publicación: 30 de julio de 2019

\begin{abstract}
Resumen
El presente artículo se propone explorar los procesos de estigmatización y falta de reconocimiento en jóvenes de sectores populares de las ciudades de Río Cuarto y Córdoba (Argentina), y su relación con la Marcha de la Gorra, entendiendo la estigmatización y falta de reconocimiento como reclamos de base de la movilización. Este objetivo se expresa en el marco de una construcción social de peligrosidad sobre la población joven, que habilita determinadas acciones por parte de las fuerzas policiales del Estado provincial cordobés, construidas como violencia institucional. La Marcha de la Gorra es una acción colectiva juvenil que denuncia estas violencias y disputa los sentidos asociados a las mismas. Atendiendo a la construcción del problema, se recurre a un abordaje cualitativo, a partir de registros etnográficos de las Mesa Organizadoras de las Marcha de la Gorra y de técnicas de entrevistas en profundidad, recuperando así las vivencias y significaciones que los jóvenes construyen sobre los estigmas socialmente asignados a ellos.
\end{abstract}

Palabras clave: estigmatización, falta de reconocimiento, jóvenes, Marcha de la Gorra, violencia institucional

\section{Institutional violence and youth political participation: the "Marcha de la Gorra" experience (Cordoba)}

\begin{abstract}
This article aims to explore the processes of stigmatization and lack of recognition of youth from the low income sectors of the cities of Río Cuarto and Cordoba (Argentina) and their relationship to the Marcha de la Gorra,
\end{abstract}

Doctora en Administración y Política Pública, Universidad Nacional de Córdoba, Argentina. Becaria Posdoctoral de CONICET. Contacto: marianalerchundi@gmail.com 2 Licenciada en Psicología. Facultad de Psicología, Universidad Nacional de Córdoba, Argentina. Contacto: mdrocio@hotmail.com.ar 
understanding this stigmatization and lack of recognition as the basis for the movement's demands. This objective is expressed within the framework of a social construction that defines these youth as dangerous, thus justifying certain actions by the police force in the province of Cordoba in the form of institutional violence. The Marcha de la Gorra is a collective youth action that denounces this violence and challenges the meanings associated with them. Considering the construction of the problem, we apply a qualitative approach based on the ethnographic records of the Organizers of the March de la Gorra as well as in-depth interviews, thus recovering the experiences and meanings constructed by young people upon their socially-assigned stigmas.

Keywords: stigmatization, lack of recognition, youth, Marcha de la Gorra, institutional violence

\title{
Violência institucional e participação política juvenil: a experiência da Marcha do Boné (Córdoba)
}

\begin{abstract}
Resumo
O presente artigo propõe-se explorar os processos de estigmatização e falta de reconhecimento em jovens de setores populares das cidades de Río Cuarto e Córdoba (Argentina), e sua relação com a Marcha do Boné, entendendo a estigmatização e falta de reconhecimento como reclamos de base da mobilização. Este objetivo expressa-se no marco de uma construção social de periculosidade sobre a população jovem, que habilita determinadas ações por parte das forças policiais do Estado provincial de Córdoba, construídas como violência institucional. A Marcha do Boné é uma ação coletiva juvenil que denuncia estas violências e disputa os sentidos associados a elas. Atendendo à construção do problema, recorre-se a uma abordagem qualitativa, a partir de registros etnográficos das Mesas Organizadoras da Marcha do Boné e de técnicas de entrevistas em profundidade, recuperando assim as vivências e significações que os jovens constroem sobre os estigmas socialmente assignados a eles.
\end{abstract}

Palavras-chave: estigmatização falta de reconhecimento, jovens, Marcha do Boné, violência institucional

\section{Introducción}

¿Cómo se ha desarrollado en Argentina la militancia en favor de los derechos humanos? ¿Cuál es el legado y su articulación con las organizaciones contra la violencia policial? ¿Cuáles son las banderas que portan? ¿Quiénes habitan hoy esos espacios? Este artículo intenta arribar respuestas a las preguntas retóricas precedentes, en orden a describir algunas dimensiones de la 
Marcha de la Gorra (MdG), entendida como acción colectiva de protesta protagonizada por jóvenes (Schuster, et al., 2006) y organizada contra la violencia policial y estatal. La estigmatización y falta de reconocimiento fueron las banderas iniciales de esta lucha que hoy lleva 11 años y se replica en numerosas ciudades de Argentina. Sobre ella nos detendremos en este artículo.

La MdG, originalmente, se realizó el 20 de noviembre ${ }^{3}$ deł 2007 en la ciudad de Córdoba Capital (Argentina); fue convocada por un conjunto de organizaciones sociales, territoriales, de derechos humanos, entre otros, con el fin de denunciar las detenciones arbitrarias llevabas a cabo por parte de las fuerzas policiales, que tenían como objetivo principal no declarado a los jóvenes de sectores populares. Dichas detenciones se encontraban enmarcadas en el Código de Faltas $(\mathrm{CdF})^{4}$, vigente en el momento ${ }^{5}$. Siguiendo a Chaboux y Monsó (2015), el CdF se sustentaba en un imaginario social instituido, a partir del cual el joven de sec-

3 El 20 de noviembre se conmemora en conmemoración a la aprobación de la Convención Internacional de los derechos de niños, niñas y adolescentes.

4 Ley Provincial 8.431. El CdF fue publicado el 19 de diciembre de 1994 en el Boletín Oficial de la Provincia. Sancionado por la legislatura el 17 de noviembre y promulgado el 7 de diciembre de 1994; actualmente existe un texto ordenado, preparado y aprobado en 2007 por la Ley 9.444 (Etchichury, 2007). Es una normativa que no solo viola la Constitución Provincial, Nacional y los pactos internacionales de Derechos Humanos a los que Argentina adhiere, sino que además vulnera principios y derechos como el de legalidad, inocencia, razonabilidad, el derecho de defensa en juicio, el de acceso a la justicia, a circular, entre tantos otros.

$5 \quad$ El 1 de abril del 2016 entra en vigencia el nuevo Código de Convivencia. Ley Provincial 10326. Aprobado el 2 de diciembre del 2015. Publicado el 28 de marzo del 2016, en el Boletín Oficial de la Provincia de Córdoba. Algunas modificaciones respecto del Código de Faltas son: ya no juzgarán los comisarios y subcomisarios, en su lugar lo harán los ayudantes de fiscales y jueces de paz, lo cual podría ser un avance, porque la policía dejaría de ser "juez y parte". No obstante, los ayudantes de fiscal no son autoridades que puedan juzgar. Otros artículos cambian apenas su nombre, como el "Merodeo en zona urbana" (art. 98 del CDF) que ahora se llamará "Conducta sospechosa" (Art. 70 Código de Convivencia, en adelante CC), mientras que el "Merodeo en zona rural" (Art. 71 CC) se mantiene intacto. Se sanciona el trabajo informal que realizan los cuidadores de vehículos, abonando la práctica de criminalización de la pobreza. Para más información, puede leerse “ ¿Jóvenes sujetos de derechos o... sin derechos? Cambios en el sistema contravencional (Córdoba, Argentina)" de Mariana Lerchundi (2016). 
tor popular es concebido, a priori, como un sujeto peligroso. Esto traía como consecuencia "detenciones masivas por Código de Faltas a jóvenes cordobeses por su condición de pobre, mestizo, barrial y joven" (Crisafulli y León Barreto, 2015, p. 202). Esa afirmación es retomada por los autores para movilizar la construcción y comprensión de peligrosidad que atraviesa a los jóvenes desde la política de seguridad de la provincia de Córdoba, cuyos sentidos son impugnados desde y por la Marcha de la Gorra (Chaboux y Monsó, 2015).

La defensa de los derechos de los jóvenes frente a la violencia policial se ubica en el activismo de los derechos humanos, remontándose a la década del ochenta en Argentina, y mucho más recientemente en Córdoba y Río Cuarto, escala local, en las que se centran nuestras indagaciones teóricas. Como señala Tiscornia (2017), pensar en la violencia institucional como un tema de investigación fue gracias al activismo legal ${ }^{6}$ de los derechos humanos que, en alianza con grupos y colectivos de demanda de justicia, inscribieron esa forma de violencia en los reclamos al Estado sobre derechos diversos.

Primero, la lucha se centró en las desapariciones forzadas de personas, sobre todo de jóvenes, como consecuencia de la última dictadura cívico-militar argentina. La causa asumió nuevas formas en la década del noventa, cuando la seguridad progresivamente tomó fuerza como demanda social. A partir de enton-

\footnotetext{
6 En este artículo no se trabaja sobre la categoría "activismo legal". La misma resulta una noción retomada por Tiscornia (2017) y Pita (2017) para dar cuenta de la militancia en materia de derechos, en orden a la construcción de la violencia institucional, desarrollada por las autoras, vinculada a las demandas elaboradas por las organizaciones y colectivos. "El activismo comenzó a ser conceptualizado, definido y analizado como un tipo particular de actor colectivo y político en sentido amplio, poseedor de un poder y una expertise específica como resultado de la consolidación de las experiencias de lucha, de la generación de espacios de litigio, de la intervención en una arena ampliada por derechos y demandas de justicia en un escenario donde el derecho internacional de los derechos humanos y el litigio estratégico ampliaba posibilidades a los movimientos sociales y a todos aquellos grupos o colectivos sociales que venían con una larga experiencia de confrontaciones y demandas de justicia" (Pita, 2017, p. 35).
} 
ces, y con más énfasis en la Provincia de Córdoba desde 2003, las "fuerzas de seguridad" comenzaron a actuar preventivamente. El ingreso de la doctrina de la tolerancia cero (Wacquant, 2004) modificó el rol de la policía, ya no preocupada por actuar proactivamente persiguiendo el delito que cometen personas individuales, sino ocupada en hostigar colectivos de personas comprendidas como productores de inseguridad.

Para prevenir posibles delincuentes, el Estado necesita de más policías, con mayores armamentos y tecnologías, porque ahora es necesario advertir comportamientos antes que tengan lugar los delitos. Esta respuesta estatal, como política de seguridad, contribuyó al incremento de detenciones arbitrarias, basadas no en delitos cometidos, sino en actitudes o perfiles indicados selectivamente como sospechosos.

En virtud de este contexto, un grupo de activistas de derechos humanos, en la ciudad de Córdoba, comenzaron a organizar una movilización en defensa de los jóvenes de sectores populares, sobre los cuales se despliega un conjunto de prejuicios policiales devenidos de la estigmatización y falta de reconocimiento de sus pautas culturales. La Marcha de la Gorra denuncia desde el año 2007 las detenciones arbitrarias y las prácticas violentas del Estado y de la policía, que agudiza sus rutinas en favor del castigo anticipatorio y sin juicio previo.

A continuación, se describen las pautas metodológicas de nuestro trabajo de campo; posteriormente, se enuncian algunas dimensiones teóricas que forman parte del contexto conceptual, priorizándose el abordaje sobre violencia institucional, y se desarrollan las aclaraciones conceptuales sobre jóvenes y participación. Esas herramientas analíticas contribuyen a reflexionar acerca de los procesos que conforman la violencia institucional y estatal, y de los jóvenes y las acciones colectivas de protesta en las que se organizan y mediante las cuales disputan dicha violencia y sus sentidos. Seguido a ello, se describen algunas dimensiones empíricas organizadas en dos ejes, por un lado, sobre la Marcha 
de la Gorra; por otro, sobre dos de sus (múltiples) lecturas y denuncias de base: la estigmatización y la falta de reconocimiento en la voz de jóvenes cordobeses de sectores populares. Para concluir, algunas reflexiones invitan a seguir pensando el temaproblema que nos convoca en este artículo.

\section{Pautas metodológicas}

En la presente comunicación nos proponemos articular 2 (dos) trabajos de campo que atienden dimensiones distintas de un proyecto de investigación marco sobre la MdG; el proceso de indagación colectivo, de tradición cualitativa y etnográfica, del que formamos parte, se inició en 2012 y, de forma ininterrumpida, avanzó en el estudio de diversos aspectos de la movilización juvenil MdG en las ciudades de Córdoba y Río Cuarto, Argentina ${ }^{7}$. La participación en este espacio de investigación y en las mesas organizativas de las Marcha de la Gorra habilitaron el desarrollo de dichos trabajos.

La MdG se define por diferentes aspectos y pliegues que la (re)construyen y atraviesan, es multiplicidad, en ella están en tensión planos contradictorios y hasta opuestos que le asignan "una cualidad enriquecida, imprevisible, abierta a los interrogantes" (Bonvillani, 2015, p. 26). Constituye en sí misma un UniversoMarcha (Gabrieloni y Bonvillani, 2015), es decir, un espacio-tiem-

$7 \quad$ El proyecto dentro del cual surgen estos trabajos fue dirigido por la Dra. Andrea Bonvillani (Proyecto SeCyT, Res. 313/16, Universidad Nacional de Córdoba). El mismo constituye parte de un proceso iniciado ya hace varios años, materializado en proyectos dirigidos también por la Dra. Bonvillani: "Prácticas de participación socio-políticas de jóvenes cordobeses pobres: un acercamiento a las formas actuales de subjetividad juvenil en la pobreza urbana"(2008-2009); “Dinámicas colectivas de anclaje territorial: Cartografiando las formas actuales de politización de los jóvenes de sectores populares de Córdoba"(2010-2011); “Grupalidades juveniles y politicidad. Explorando los sentidos políticos de las prácticas culturales colectivas de los jóvenes de sectores populares cordobeses" (2012-2013); "La Marcha de la Gorra como experiencia de subjetivación política de jóvenes de Córdoba (Argentina)" (2014-2015); y “Diez años de la Marcha de la gorra: memorias de una lucha juvenil cordobesa" (2016-2018). 
po específico en el que conviven pluralidad de voces, sentidos y experiencias que terminan por constituirla y formarla. La Marcha es alegría festiva de los jóvenes de sectores populares, es tristeza por la estigmatización y prejuicios que recaen sobre ellos, es dolor y sentido de injusticia por las etiquetas que los atraviesan.

En el marco de este universo-marcha, este trabajo se propuso explorar los procesos de estigmatización y falta de reconocimiento en jóvenes de sectores populares de las ciudades de Río Cuarto y Córdoba (Argentina) y su la relación con la Marcha de la Gorra, entendiendo la estigmatización y falta de reconocimiento como una de las denuncias de base de la movilización. Para cumplir con ese objetivo se trabajó con entrevistas en profundidad a jóvenes, varones, de sectores populares (Taylor y Bogdan, 1990) ${ }^{8}$; se pretendió de esa forma ahondar en las repercusiones que tienen las experiencias de detenciones arbitrarias en los jóvenes y otras experiencias de su cotidianeidad, particularmente leyéndolas desde procesos de estigmatización y falta de reconocimiento.

También se analizaron entrevistas en profundidad con jóvenes militantes, de clase media, de diferentes organizaciones sociales, políticas y territoriales, que forman parte de la Mesa Organizativa de MdG en la ciudad de Córdoba'; de esta manera, se pretendió acceder a las construcciones y procesos que se desarrollan en dicho espacio de lucha. Sumado a lo anterior, se re-

Las entrevistas fueron realizadas entre los años 2014 y 2017. En este trabajo se incluyen fragmentos de narraciones de Lautaro, Champi, Huapi, Raiquen y Catriel. Estos jóvenes fueron detenidos por la policía, en sus relatos se pudo reconstruir esos episodios donde se ven vulnerados algunos derechos constitucionales que no se abordan en este artículo, pero fueron analizados detenidamente. Asimismo, en las entrevistas se reconstruyen otras dimensiones de sus trayectorias vitales tales como educativas, laborales, familiares, etc. Resulta necesario aclarar que los fragmentos citados forman parte de un corpus más amplio de entrevistas. Con cada uno de ellos hubo al menos 2 o 3 encuentros generados a los fines de las entrevistas, mientras que también hubo interacciones en otros espacios extra entrevistas. Habilitados en todos los casos por la red de relaciones establecidas desde la Marcha de la Gorra.

$9 \quad$ Estas entrevistas se realizaron entre junio y septiembre del año 2017. En el presente trabajo, se incluyen fragmentos de la entrevista con Deadpool, militante de organizaciones en procesos de toma de tierra y por el derecho a la tierra y vivienda. 
tomaron registros etnográficos realizados por las investigadoras, como parte de la observación participante (Guber, 2011) en los procesos organizativos y en las marchas mismas, de las ciudades de Río Cuarto y Córdoba ${ }^{10}$.

Por otra parte, a través del análisis del discurso (Merlino, 2012), se observaron fragmentos de los documentos públicos de diversas ediciones de la MdG, para retomar las lecturas y construcciones realizadas por los mismos protagonistas de la marcha sobre violencia institucional. Finalmente, la interpretación y la codificación de los materiales empíricos recogidos durante el trabajo de campo posibilitaron la construcción y la puesta en diálogo de las subdimensiones y categorías emergentes. Para ello se tomaron herramientas de la Teoría Fundamentada en los Datos (Glaser y Strauss, 1967), que le imprimió al proceso un carácter abierto y dinámico, especialmente en lo referido a las relaciones entre el material producido en el trabajo de campo y la etapa de análisis. Finalmente, se utilizó el software de análisis cualitativo Atlas.ti para la organización e interpretación del material recabado.

\section{Violencia institucional y policial}

Antecedentes inmediatos sobre el sentido asignado en los artículos científicos a esta categoría indican que, en la década del ochenta, se utilizó la noción de "violencia institucional"11 para dar visibilidad a una forma de violencia policial naturalizada, cotidiana y aceptada socialmente. En esa década, junto con el re-

\footnotetext{
10 Dichos registros abarcan desde el año 2015 al 2018, en la Mesa Organizativa de MdG en Córdoba, y desde 2014 a 2018 en la Mesa Organizativa de MdG en Río Cuarto.

11 Se advierte que en el presente artículo no se aborda la noción de "violencia", sino la de "violencia institucional". Es por ello que se deja fuera una larga trayectoria de elaboraciones teóricas sobre la categoría "violencia". Como indica Pita (2017), se alude a la historia política local del concepto, que visibiliza ciertas problemáticas relacionadas con las instituciones del Estado.
} 
greso de la democracia, Argentina volvió a mirar los derechos humanos: salir de la última dictadura cívico-militar exigió poner en palabras los delitos de lesa humanidad cometidos por los militares que recayeron mayoritariamente sobre jóvenes; es decir, fueron jóvenes las víctimas del terrorismo de Estado.

La violencia institucional surge en este contexto para separarse de la violencia política, de la represión y de las ejecuciones de la década precedente y nombrar a las

formas cotidianas de hostigamiento violento de las policías a determinados grupos (...) Una forma de violencia que tenía su expresión más notoria en el llamado "gatillo fácil"12, pero que, para que este exista, otras formas de violencia más usuales debían habilitarla. (Tiscornia, 2017, p. 27)

La violencia ejercida por las fuerzas de seguridad de la democracia tenía muchos vínculos con las ejercidas durante la dictadura. Por entonces, la pregunta que atravesaba a militantes e investigadores era la siguiente: ¿los hechos violentos, ejercidos por las fuerzas de seguridad, pueden comprenderse como violaciones a los derechos humanos? Eran muchas las coincidencias con las prácticas recientes, y se pudo entender que cambiaba el sujeto de persecución, pero las prácticas se mantenían.

En 1993, el Informe sobre Violencia Institucional y Urbana es el primero que inaugura las publicaciones del Centro de Estudios Legales y Sociales en materia de violencia institucional. En ese informe se habla concretamente de la violencia institucional como violencia policial y se operacionaliza la categoría a partir de (1) especificaciones de los tipos de hecho de violencia policial, (2)

12 Se denomina "gatillo fácil" a las muertes producto del accionar de las fuerzas de seguridad (Llobet, 2015). Actualmente, sus sentidos están en disputa y organizaciones de derechos humanos empiezan a llamarlas "homicidio policial". Desde la Mesa Organizativa de MdG Córdoba, desde 2010, se nombran en su documento público como "asesinatos". Desde el año 2011, como "fusilamientos". 
abusos policiales y de agentes de fuerzas de seguridad, homicidios y lesiones cometidos por agentes de seguridad, (3) informe sobre torturas. Es decir, es un tipo de violencia articulada con formas de afectación del cuerpo, que habilita a registrar diversos flagelos experienciados por las personas (CELS, 1993).

Por su parte, Pita (2010) indica que, en esta década, los familiares de víctimas de "gatillo fácil" se autonombraron también como víctimas de la represión o de la impunidad, mas no como víctimas de la violencia institucional. La autora advierte que esta identificación gana terreno avanzados los años dos mil, en el marco de la creación de la Campaña Nacional contra la Violencia Institucional y/o con la creación de la Procuraduría contra la Violencia Institucional, por parte del Ministerio Público Fiscal de la Nación.

Hacia fines de los noventa, Guemureman y Gugliotta (1998) amplían la noción, entendiendo que la violencia institucional es aquella ejercida sobre las personas en posición de vulnerabilidad, con base en la aplicación de la fuerza física o en la coerción psicológica. Ésta representa una noción amplia de violencia institucional, no reducida a las agencias policiales del Estado; se incluye la dimensión física al igual que la subjetiva, también denominada "dimensión moral" de la violencia (Rodríguez Alzueta, 2014).

En la primera década del siglo XXI la categoría parecía estar instalada. Las preguntas que acompañan a estos años resultan de su permanencia e incremento y son conceptualizadas por el CELS (2000, p. 1) como "patrones de conducta arraigados en el modo en que las instituciones ejercen la función de seguridad". En esta década, la violencia institucional, asociada a la violencia estatal, como lo proponen Guemuremen et al. (2017), habilita responsabilizar al Estado, por un lado, en su faz punitiva, por ejercer violencia y, al mismo tiempo, denunciar su rol central para garantizar los derechos humanos.

Por su parte, la Comisión Provincial de la Memoria de la Provincia de Buenos Aires, en 2012, publicó un texto en el que señala 
la violencia institucional como una deuda de la democracia. Y en ese marco concluyen:

hablamos de violencia institucional porque es una violencia ejercida desde las agencias estatales. Se trata de prácticas cuya frecuencia, masividad y repetición sostenida en el tiempo obligan a conceptualizarlas como rasgos estructurales del funcionamiento policial-judicial y rechazar su definición en términos de trasgresión individual. Se trata de conductas aprendidas e incorporadas en el devenir cotidiano de las rutinas policiales, penitenciarias y judiciales. (Comisión Provincial de la Memoria, 2012, p. 14)

Finalmente, es el propio Congreso de la Nación, motorizado por organizaciones sociales, que instituye el 8 de mayo como "Día Nacional de la Lucha Contra la Violencia Institucional" (Ley 26.811). Se toma como referencia la Masacre de Ingeniero Budge (1987), en la que efectivos policiales asesinaron a tres jóvenes, hecho reconocido como los primeros casos de gatillo fácil en democracia. La ley detalla, por un lado, que tiene como objetivo recordar las violaciones a los derechos humanos ocasionadas por las "fuerzas de seguridad"; al mismo tiempo, insta al desarrollo de una "concepción democrática de la seguridad respetando la plena vigencia de los Derechos Humanos, la sujeción irrenunciable de las fuerzas de seguridad al poder político y la protección de los derechos de los grupos más vulnerables de la sociedad" (Ley 26.811, art. 2, p. 1). Es decir, el Estado formaliza esta categoría para nombrar las violaciones de derechos producto de sus fuerzas de seguridad.

Lo anterior viene a reponer el eje en el Estado. En ese sentido, hay que recordar el origen de la categoría, surgido al calor de las luchas de familiares de víctimas de la violencia de las agencias punitivas estatales (Guemureman et al., 2017). Sin desconocer las derivas que ha tenido este concepto en otros campos disciplinares, el ribete más interesante de continuar usando la noción de 
"violencia institucional" sería comprenderla como una violencia arbitraria, alejada del respeto de los derechos humanos, que convive con el mundo del Derecho, con las prácticas regladas y legales de la cadena punitiva (en el sentido asignado por Daroqui y López, 2012). Es un modo de violencia estructural, que forma parte de los patrones de actuación del Estado de Derecho, una violencia producida por sus agencias $\mathrm{y}$, por tanto, institucional.

La Marcha de la Gorra encarnará, primero, la lucha contra la violencia institucional, pero luego pondrá en debate esta categoría, como se observa en los resultados. Siguiendo a Pita (2017), se advierte que poner el eje en esta categoría política local, es decir, en el concepto localizado e históricamente situado, se alinea en el marco de discusiones sobre violencias del Estado y derechos humanos, políticas de seguridad y juventudes, construcciones de peligrosidad y estigmatizaciones, y faltas de reconocimiento. Por cuanto esta categoría que pretendemos mostrar sirve para situar una de las discusiones alojadas en la Marcha.

Nuestra posición teórica y política se construye como experiencia distante que acompaña la experiencia próxima (Geertz, 1994, en Pita, 2017). Esto es, experiencia de afectaciones de las violencias impartidas por el Estado que se entraman con prácticas de investigación, y juntas contribuyen a la denuncia del desempeño de las fuerzas policiales. Con todo, desde la posición que asumimos, no se pretende nombrar la violencia institucional y estatal como un concepto dado, sino como una noción con horizonte político y posible de ser transformada.

\section{Jóvenes y participación política}

En este trabajo se tiene en cuenta los parámetros sociodemográficos del Instituto Nacional de Estadísticas y Censos de Argentina, (INDEC, 2015), para identificar que las personas entre 15 y 29 años de edad son consideradas jóvenes. Este recurso de orden metodológico es tomado de la mano de un conjunto de perspectivas trabajadas en un texto anterior, en el que explicita- 
mos nuestra posición crítica e interdisciplinar para analizar esta categoría, central en el trabajo de indagación teórica y construcción del objeto de estudio (Lerchundi, 2015). La idea central de la que partimos es comprender al joven como sujeto de derecho, atravesado por inequidades y desigualdades sociales, políticas, económicas y culturales, y al que se le asigna el papel protagónico del desarrollo de sus comunidades.

En la diversidad de mundos, experiencias y modos de vivir la juventud, en la segunda parte de los resultados nos centramos en las personas jóvenes, de sectores populares, de sexo masculino. Eludir la perspectiva de género no es por desconocimiento de cómo la violencia institucional y estatal afecta a las mujeres y al colectivo LGTBIQ+, sino por entender que los varones son los clientes típicos del sistema penal y contravencional (Guemureman, 2015), es decir, quienes padecen de modo directo y con mayor frecuencia dicha violencia.

Asimismo, no hablamos de "jóvenes pobres", sino de "jóvenes de sectores populares". Lo hacemos porque el grupo poblacional con el cual trabajamos está atravesado por condiciones de vida desfavorables, precariedad material y desafiliación laboral; pero además son jóvenes cuyas prácticas culturales, sus modos de vestir, hablar y estar en el espacio público, no responden a los parámetros hegemónicos establecidos por los sectores de posición social más acomodada (Castel, 2013; Míguez y Semán, 2006).

Por otra parte, en el primer campo de resultados se incluyen los activistas de la Marcha de la Gorra. En ese espacio, participan las y los jóvenes no solo de sectores populares, sino principalmente de sectores medios y universitarios que se organizan frente a la violencia institucional y estatal. Este grupo podría leerse desde el enfoque generacional (Vommaro, 2015), dado que la Marcha es habilitada por sujetos cuyas edades, en muchos casos, desbordan los parámetros sociodemográficos expuestos arriba. Sin embargo, trabajaremos con dicho recorte con el fin de homogeneizar las lecturas del universo de entrevistados. 
Como mencionan Vommaro y Vázquez (2008), en Argentina, en la década de los noventa, se produce un conjunto de transformaciones políticas que son expresión de una crisis de representación. Con el retorno a la democracia fueron definidos los contornos de la "buena política", caracterizada ésta por tener como actor principal al ciudadano o ciudadana, cuyo acto político por excelencia era la participación electoral a través del voto, siendo representado a partir de la actividad de los partidos políticos (Merklen, en Vommaro y Vázquez, 2008). Sin embargo, rápidamente se evidenció la emergencia de modalidades de organización colectiva y participación política por fuera de las vías institucionales de implicación con la política, dando cuenta de la formación de nuevos repertorios de movilización social y actores político-sociales.

En relación con esto, continúan los autores, se consideró que una de las bases de dicha crisis de representación se encontraba, en realidad, en una crisis de la participación política juvenil. Este hecho ocurría porque los jóvenes se caracterizaban por ser desinteresados, desencantados y apáticos; esta fue una idea ampliamente difundida en ese entonces.

Alvarado, Borelli y Vommaro (2010) explican que los jóvenes son constituidos como sujetos por un enorme conjunto de instituciones, discursos y prácticas, es decir, formas de organización de la cultura y el Estado dominantes. Sin embargo, es importante remarcar que, también, la constitución subjetiva de dichos jóvenes se ha dado a partir de formas alternativas, paralelas y muchas veces fuera de ese conjunto de prácticas e instituciones, o en interacción con ellas, generalmente desde una postura contestataria. De modo tal que se entiende que los jóvenes producen pluralidad política, intervienen y participan de la vida pública, en organizaciones existentes y en otros espacios que crean a través de una comprensión crítica de la cultura, la política y el Estado.

Los jóvenes acerca de los cuales nos referimos en este artículo, por un lado participan en la Marcha de la Gorra, habitando las calles, construyendo sentidos que dialogan con y en la mesa or- 
ganizativa de las Marchas de la Gorra de Córdoba y Río Cuarto. Por otro, son jóvenes de sectores populares sobre los que se despliegan las prácticas de estigmatización y falta de reconocimiento que se detallan a continuación.

\section{Resultados}

\section{Marcha de la Gorra}

La MdG irrumpe en noviembre de cada año por las calles del centro de Córdoba. En el plano teórico, puede concebírsela como una "forma modular clásica de la acción colectiva" (Tarrow, 1997, p. 190); en este sentido, Roldán, Alonso y Farías Iten (2016) la entienden "como una acción de protesta que busca visibilizar un conjunto de problemáticas que afectan, fundamentalmente, a jóvenes de sectores populares" (p. 168) y que se vinculan con la implementación del CdF. Este último, inscribiéndose como parte de la política de seguridad de la provincia de Córdoba, se constituye como herramienta legal que materializa determinada concepción represiva sobre los modos de "aseguramiento público" (Roldán et al., 2015).

Como menciona Bonvillani (2015), la MdG es una acción colectiva que, considerando el crecimiento participativo que progresivamente ha ido registrando, necesita de altos niveles de organización. Por esa razón, las reuniones de la Mesa Organizativa de la MdG comienzan meses antes de la fecha histórica de la misma (20 de noviembre), con una frecuencia semanal. La Mesa se encuentra integrada por diversas organizaciones sociales, políticas, culturales, familiares de víctimas de "gatillo fácil", organizaciones de derechos humanos, académicos, etc., que asisten de forma abierta y voluntaria ${ }^{13}$. Funciona a partir de la división en

\footnotetext{
13 Interesa remarcar que ésta no es la única manera de participar en la MDG, ya que muchos autoconvocados, colectivos artísticos, murgas, espacios políticos, organizaciones de base territorial, etc. no forman parte de la Mesa Organizativa, pero se encuentran en las calles el día de la Marcha.
} 
comisiones de trabajo que se ocupan de diversas dimensiones de la marcha, tales como seguridad, artística, comunicación, documento y finanzas, y logística ${ }^{14}$.

La autora explica que esta forma de organización responde a una lógica asamblearia, lo que implica que la toma de decisiones se produce sobre la base de la discusión en un espacio común, en dos momentos diferentes: en un principio se debaten temas en cada Comisión, que luego son socializados en la Reunión Plenaria, donde finalmente se resuelven.

Los consensos alcanzados en cada edición de la MdG se encuentran condensados en la consigna que representa cada año a la marcha; el documento público que se lee en el escenario al finalizar cada movilización se constituye como una extensión de dicha consigna, en la que se registran las posiciones asumida por los espacios que conforman la Mesa Organizativa de la Marcha. Considerando lo dicho, aquello que se registra en los documentos se vuelve un importante ámbito de disputa para las diferentes organizaciones y espacios que confluyen en la MdG, y, por eso mismo, es en este trabajo entendido como una herramienta central para analizar las construcciones sobre las violencias estatales y los procesos sociales en los cuales se asientan.

En el marco de la Marcha de la Gorra, los debates en torno a las nociones de "violencia institucional" se hicieron presentes, produciéndose diferencias en los procesos de construcción política entre las diferentes mesas organizativas de MdG en ciudades distintas.

\footnotetext{
14 Desde el año 2014 comenzó a funcionar la llamada Comisión Enlace, como subcomisión de la de Comunicación y con el fin de articular con otras ciudades y provincias. En el año 2018 se logró acordar una fecha nacional para marchar (23 de noviembre) en las ciudades de San Francisco, Rio Cuarto, Villa María, Mina Clavero y Córdoba capital (todas en provincia de Córdoba) y en las ciudades de Rosario (provincia de Rosario) y en Mar del Plata, La Plata, CABA (en provincia de Buenos Aires). En el barrio de La Matanza (ciudad de Buenos Aires), se realizó el 1 de diciembre, y en la ciudad de Tandil (provincia de Buenos Aires), el 7 de diciembre de ese año de 2018.
} 
En Río Cuarto se configuraron preguntas en torno a violencia institucional como representación difusa de la denuncia ${ }^{15}$. ¿Puede un vecino de un barrio de la ciudad, sin formación académica, comprender de lo que habla? ¿Entenderán los medios de comunicación qué se menciona con "violencia policial naturalizada"? ${ }^{16}$ Algunos de los miembros organizadores sostuvieron que la noción de "violencia" es aprehensible para toda la ciudadanía, pues de algún modo supone el reparto arbitrario del poder, la distribución diferencial ejercida desde una posición privilegiada en detrimento de otros.

La misma claridad semántica no ocurre con "institucional", puede desbordar la idea de agencias del Estado e incluir a instituciones privadas. En el primer documento de la Marcha de la Gorra, en Río Cuarto, en 2014, se la llamó "abuso policial". En el segundo, en 2015, se habló concretamente de las "prácticas policiales violentas": detenciones arbitrarias, tortura en las dependencias policiales, "gatillo fácil". En el tercer documento, en 2016, se mencionó a la violencia institucional de la mano de la represión estatal. En 2017 se habló de "políticas represivas", categoría insistente a lo largo del texto, que llega a reemplazar el sintagma "política de seguridad". Mientras que, en el último, en 2018, se retoman las categorías "violencia institucional" y "violencia policial", usadas como sinónimos ${ }^{17}$.

La noción de "violencia institucional" solapa diferentes órdenes jurídicos, teóricos, empíricos y políticos. Aloja una diversidad de prácticas violatorias de los derechos humanos que deben

15 Los siguientes análisis se realizan en base a los registros etnográficos realizados en los procesos organizativos de MdG Río Cuarto, del año 2014 al 2018.

16 Pregunta devenidas de los registros etnográficos, año 2014, en los plenarios. Lo cual explicita las primeras discusiones sobre la utilización de la categoría. Sin embargo, en años posteriores se retoman las disputas semánticas en orden a la construcción del documento público, esto es, registros particularizados de la Comisión Documentos.

17 La MdG Río Cuarto no cuenta con página web, sino con fans page de la red social Facebook e Instagram. Los documentos, si bien públicos, no se encuentran en las redes, sino que se accede a ellos a través del corpus elaborado en el marco de la etnografía. 
ser entendidas como masivas y repetidas a lo largo del tiempo. Esta idea sobre ella, la búsqueda de las singularidades locales en Río Cuarto, son las que permiten a la Marcha de la Gorra actuar sobre esta forma de violencia, a pesar de que, en los documentos de la organización, es nombrada también de otros modos. Sin embargo, durante las reuniones organizativas de la movilización de 2018 se habló de la necesidad de dar un deslizamiento desde comprenderse como una movilización contra la violencia institucional hacia una lucha antirrepresiva y entenderse como activistas de un espacio más amplio que se entrama con las demandas del colectivo feminista, contra el "gatillo fácil", y la represión de la protesta social. Demandas presentes no solo en el campo local, sino también en el escenario nacional.

En la ciudad de Córdoba se realiza un "quiebre" de sentidos que lleva a que la MdG, desde 2016, se enuncie en contra de una violencia estatal, dejando de lado la concepción de violencia institucional. Importa decir que, con el paso de los años, el universo de la demanda de la MdG ha ido complejizándose, y se incorporaron otras luchas a las razones de por qué se marcha, como puede ser: la criminalización de la protesta, el reclamo por justicia en casos de gatillo fácil, allanamientos sin órdenes judiciales en las villas, persecución de trabajadores informales y trabajadores sexuales, represión y hostigamiento a jóvenes de sectores populares, violaciones a los derechos humanos y abusos en cárceles y barrios pobres, políticas públicas, nacionales y provinciales, que limitan cada vez más el acceso a derechos básicos (tierras, educación, alimentos, entre otros), y la lista continúa. Todo lo anterior se ve condensado en la consigna de la MdG en 2016: “¿Cuánto más? El Estado es responsable"18, desde la cual se construye al Estado como su interlocutor directo.

18 Puede leerse más en http://marchadelagorra.org/carta-abierta-al-estadopolicial-2/ 
En el documento público de ese año se desarrolla la idea de "violencia estatal": violencias (múltiples) que se viven en los cuerpos (de jóvenes de sectores populares, sí, pero también de mujeres, cuerpos sexogenéricamente disidentes, trabajadoras sexuales, trabajadores de la economía popular, carreros, militantes de partidos y organizaciones sociales, artesanos, piqueteros, negros, pueblos originarios, estudiantes, comunicadores alternativos, pobres). Esta violencia no es entonces un "exceso de fuer$\mathrm{za}^{\prime}$ por parte de agentes policiales, reflejada en hostigamientos, persecuciones, detenciones arbitrarias, "gatillo fácil", torturas y asesinatos en comisarías y cárceles, sino un modelo de Estado que, mediante la implementación de políticas y de diversas instituciones y agentes, construye una realidad en la que hay "ciudadan $x$ s de primera y de segunda" (fragmento del documento de la décima edición de Marcha de la Gorra Córdoba). Un Estado que violenta integralmente todos los derechos de las personas, con medidas de ajuste y represión. Desde esta construcción, la violencia estatal incluye, pero al mismo tiempo excede, a la violencia institucional ${ }^{19}$.

La noción fue sostenida y reconstruida durante las dos ediciones de MdG siguientes: en el 2017 la consigna fue "El Estado nos mata, sus medios lo bancan, nuestra lucha avanza", haciendo una alusión clara a las construcciones y complicidades que se dan entre entidades estatales; un ejemplo de ello sería el aval que poderes como el legislativo y el judicial dan a las prácticas policiales, en términos de absolver a agentes oficiales involucrados en casos de "gatillo fácil". Sumado a esto, ese año se dio, de forma potenciada, la persecución a pueblos mapuches (tanto en Chile como en Argentina), y se relacionó con la desaparición y muerte de Santiago Maldonado; en este contexto, los medios de comunicación generaron (des)información sobre la situación, y

19 Para más información, puede accederse al documento desde http:// marchadelagorra.org/carta-abierta-al-estado-policial-2/ 
presentaron estas luchas como conspiraciones peligrosas que debían ser erradicadas ${ }^{20}$.

En 2018, la consigna de la marcha fue "Terrorista es el Estado, no quien tenés al lado". Ese año se caracterizó por ser un año de lucha de diversos agentes y grupos sociales y, además, de multiplicación de fuerzas policiales (policía federal, policía de seguridad aeroportuaria, policía barrial, entre otras), dándose una fuerte militarización de la cotidianeidad ciudadana, con presencia incluso de la Gendarmería Nacional, localizada especialmente en barrios populares y villas. En este sentido, MdG se posicionó denunciando que se buscaba construir un "enemigo interno", que socialmente implanta el miedo permanente por "quien tenés al lado", e invisibiliza las violencias ejercidas por parte del Estado ${ }^{21}$.

\section{Las banderas iniciales de la Marcha de la Gorra}

¿Porquéabordarlaestigmatización y la falta dereconocimiento como banderas iniciales de la MdG? La demanda central de la misma se organiza en torno a la política de seguridad provincial, considerada violatoria de los derechos humanos de los grupos sociales más vulnerables. Estos sujetos adscriben a cierto modo popular de experienciar la cultura juvenil, configurada por los vecinos como sujeto-problema.

Al decir de Rodríguez Alzueta (2014), detrás del olfato policial se encuentra el olfato social. Hay una continuidad entre las prácticas discriminatorias de la sociedad con las prácticas policiales violentas: las primeras crean condiciones de posibilidad para que el policía en el territorio actúe con diversidad de malos tratos que son legitimados por el propio entorno social. En esa tesis, reside la necesidad de la MdG de reponer los sentidos arre-

\footnotetext{
20 Estas lecturas pueden ampliarse desde http://marchadelagorra.org/ documento-de-la-11-mdlg/

${ }^{21}$ Puede accederse al documento desde http:/ / marchadelagorra.org/documento12-marcha-de-la-gorra/
} 
batados a los jóvenes, entendiendo que el miedo social es uno de los efectos simbólicos de la adjetivación como sujetos peligrosos que recae sobre el colectivo juvenil. En otras palabras, la policía persigue a los jóvenes por sus rostros, sus formas de estar en el espacio público, por sus elecciones culturales y, ante ello, la MdG hace del estigma su emblema (Reguillo, 2012).

Goffman (1963) había establecido que los estigmas eran signos corporales que exhiben algo negativo del sujeto, identificados mediante marcas visibles, principalmente desarrollados en la vida pública y que dificultan la plena aceptación social. Pero en tanto inquietud por la visibilidad, el autor se preguntaba en qué medida el estigma sirve para comunicar que el individuo lo posee. ¿Los jóvenes de sectores populares son poseedores de los estigmas que portan? A través de la imagen corroída de sí mismos, ¿intentan actuar de acuerdo con lo que se espera de ellos?

Los estereotipos son las creencias referidas a un grupo, previamente asignadas y compartidas por los miembros de una cultura. Si el estereotipo está ligado a evaluaciones negativas es un prejuicio (Kornblit, Camarotti y Di Leo, 2014). Para Hall (2010), el estereotipo reduce a las personas "a unas cuantas características simples, esenciales que son representadas como fijas por parte de la Naturaleza" (p. 429). Mientras que la estigmatización es el proceso por el que los atributos negativos se adjudican a un sujeto o grupo y sellan una esencia estable e inmutable. Cuando se combinan la estigmatización y el prejuicio, a través de conductas de rechazo hacia grupos y sujetos específicos, hablamos de discriminación (Kornblit, Camarotti y Di Leo, 2014).

Por su parte, Segato (2006) subraya la importancia de comprender que el cultivo del prejuicio, propio de la intimidad, alimenta la discriminación en el ámbito público, que se naturaliza y toma carácter a-histórico, y hasta omnipresente. La autora habla de racismo e invita a des-esencializar las supuestas cualidades "naturales" que determinan la inferioridad de ciertos grupos sociales. 
Algunos estudios (Chavez, 2005; Bonvillani, 2015) coinciden en que la estigmatización a los jóvenes de sectores populares ha permitido la construcción de un sujeto desacreditado. El prejuicio convive con el estigma y produce estereotipos de posibles detenidos que uniforman la heterogeneidad del universo popular. Los jóvenes son sospechosos, el imaginario selectivizado de los vecinos y la sociedad, primero, y del policía, después, termina por temer y detener a los mismos sujetos. Ese "olfato" o "saber policial", ganado en la experiencia como agente de seguridad, es la puerta a las violencias e injusticias que la MdG denuncia.

Se toma como referencia la estigmatización y la falta de reconocimiento para identificar el atravesamiento de esas dimensiones en la violencia institucional, en quien la recibe, y en cómo esa articulación se vincula con la organización juvenil y la lucha colectiva. A continuación se expone algunos ejemplos en los que el estigma aparece en las entrevistas realizadas a los jóvenes, cuyos "usos" y escenarios son diversos. Veremos cómo el estigma aparece en el relacionamiento horizontal, como así también en encuentros con la policía. Se advertirá, además, formas de confirmarlo o negarlo.

El año anterior, con otro chico, había una parejita peleando, yo voy y los separo. Y en eso los testigos que había dicen que yo quería robarles. (...) Quedé imputado en la causa, pero yo nada que ver. De los otros chicos (denunciados) no se presentó nadie. Yo me presenté. (Catriel, comunicación personal, 3 de agosto de 2016)

El joven describe una situación que no se corresponde con la denuncia, ante ella intenta buscar razones, argumentos para explicar la imputación. Catriel sostiene que se construye sobre su rostro, rasgos heredados de la piel, modos aprendidos culturalmente, formas de habitar el espacio propias de las masculinidades de los sectores populares, pero no por sus actos, dado que no cometió ni tuvo intenciones de efectuar un delito. 
Dice Elias (2003): “un grupo sólo puede estigmatizar efectivamente a otro en la medida en que se encuentre bien instalado en posiciones de poder a las que el otro grupo ve negado el acceso" (p. 224). Con Elias entendemos que ese poder construyó un muro simbólico entre los denunciantes y el joven. Sin embargo, a pesar del orden establecido, de las desiguales posiciones que denunciantes y denunciados asumen, del ejercicio del poder, Catriel utiliza discursivamente sus estigmas, en tanto neutralizadores de una denuncia construida sobre la base de un discurso racista (Le Breton, 2002), que atraviesa la condición de subalternidad de Catriel.

Es decir, ante la distinción de un nosotros -incluidos y aceptados-, Catriel entiende que ocupa el lugar del otro - excluido y rechazado- y que por ello fue denunciado. El joven identifica algunos referentes empíricos que vuelven esencia su persona, como su color de piel trigueña, vestimenta, peinado, uso de capucha, zapatillas, su apariencia física, sus tatuajes y cicatrices. En este caso, el estigma aparece confirmándose, por reconocerse portador de los elementos que desde afuera lo señalan.

En otros casos los jóvenes confirman el estigma, ya no para neutralizarlo sino para enfrentar una determinada circunstancia. Esto no representa una práctica aleatoria, sino que existe un entrenamiento devenido de experiencias anteriores a las prácticas de socialización primarias (Benedicto, 1995), en las que el sujeto decide cómo actuar conforme a las ventajas -implementando una capacidad consciente e intencional específica del caso-, pero también una emocionalidad más de tipo circunstancial, es decir, un potencial corporal y subjetivo que se pone en marcha en cada encuentro policial.

La forma de comportarse ante el estigma ya había sido anticipada por Goffman (1963). El autor propone dos formas de actuar ante él: su ocultamiento, el rechazo para evitar la descalificación. Mientras que un segundo tipo de comportamiento significaba vivir el estigma como una marca de distinción. Esta última ope- 
ratoria es llamada por Reguillo (2012) como "proceso de emblematización", entendiéndolo como volver positiva las cargas negativas. Dice un joven:

Y cuando la yuta nos apuntaba con la ithaca, el wacho 22 me dijo que me iba a cagar a tiros. Y yo le dije que tenía alta 45 para él y balas para la yuta. (Champi, comunicación personal, 10 de enero de 2017)

Champi describe disputas horizontales con otros jóvenes, broncas heredadas de amigos, transferidas, confirmadas y sostenidas por él. En este caso, consecuencia de ciertas alianzas y complicidades de las familias de sus antagonistas con algunos agentes de las fuerzas de seguridad, lo retiran forzadamente de una discoteca local. La situación ocurre en un boliche bailable donde, después de algunos disturbios lo sacan del lugar; allí recibe golpes del policía y amenazas del joven con quien mantiene la disputa.

En esta circunstancia, Champi redobla la apuesta de la advertencia, confirma el estigma que lo apunta como "sujeto-problema", lo asume positivamente y enfrenta al policía y al joven con una amenaza mayor. Es una práctica construida en la experiencia cotidiana, producida mediante la participación en el espacio social, un modo de no devaluar la masculinidad frente a su grupo de pares. Se advierte una apuesta escénica de lucha junto o con el estigma; mediante un hacer reglado disputa sentidos de prestigio y legitimidad territorial (Cozzi, 2016) con apoyo y promesa de mayor violencia.

En otros casos, el estigma aparece como humillación, produciéndose prácticas que lo niegan y se alejan de esas marcas que lo describen. Como es el caso de Lautaro, cuando detalla una imputación social de un hecho que no habían cometido:

22 Categoría nativa para indicar joven. 
Cuando llegué había un montón de gente junta que decía "un negrito de gorrita, uno de gorrita" y mi amigo apareció caminando por las vías y yo no entendía nada. Miro así y venía la policía, pararon los móviles. Habían dicho que mi amigo había estado pateando, pateando, pateando la puerta de la casa, que el dueño de la casa no estaba y alguien hizo la denuncia. Yo después escuché cuando llegó el vecino que era dueño de la casa, que no tenía la puerta pateada y que estaba todo bien, que no habían robado, nada. Se ve que alguien se asustó y denunció que estaba mi amigo sentado, pero no estaba haciendo nada. Cuando me vieron que yo venía caminando caí yo también. Y cuando nos llevaban yo les decía "que por qué nos llevaban si no estábamos haciendo nada y que había escuchado que no había pasado nada", pero no me respondían. (Lautaro, comunicación personal, 8 de mayo de 2016)

Los estigmas señalados por los vecinos se reducen al color de la piel y a la gorra, accesorio de vestimenta identificador de peligrosidad. Su emblematización ha sido usado por la Marcha de la Gorra para darle nombre a la lucha de los jóvenes de sectores populares. Esos estigmas anulan la posibilidad de diálogo y producen una negación del derecho al espacio urbano.

Por su parte, y esta misma línea, Champi cuenta experiencias de sus inicios laborales e indica que fue nombrado como " $\mathrm{el}$ negrito" o "el cordobés", que provenía de sectores empobrecidos. Cuyos registros aún se oyen:

(...) me como las eses, tengo errores, la erre no la pronuncio bien. (Champi, comunicación personal, 19 de julio de 2016)

Para el joven, su forma de hablar, propia de los sectores populares cordobeses, se convirtió en una marca, un estigma que lo descalifica y desautoriza, lo torna extraño y peligroso, convirtiéndose en motor y causa de culpas falsas, en el marco de sus primeros trabajos tomados a sus tempranos 12 años de edad. 
En otras circunstancias, y con un uso negativo el estigma, Lautaro relata que, en el marco de una demora en la vía pública, los agentes de seguridad lo señalan como falopero y choro. Se llama "falopero" al sujeto que consume drogas y "choro" al que roba. Lautaro resiste y niega el estigma:

Y dije "decime, decime que yo sé cómo son ustedes y quieren que termine siendo eso que me dicen, quieren que haga algo para llevarme, pero no". Te tratan de negro, de falopero, de choro, de todo. (Lautaro, comunicación personal, 18 de mayo de 2016)

El joven habla de la profecía autocumplida (Tonkonoff, 2003; Becker, 2009), noción configurada a partir de los estigmas reconocidos socialmente, fundidos como callo en los jóvenes; desde esas nociones la policía persigue y castiga. La profecía se juega como algo que está dicho y no es posible de cambiar; un profeta que lo establece y el sujeto alcanzará los resultados indicados, confirmando de ese modo la profecía. Es decir, el estigma, la etiqueta negativa, genera que el sujeto asuma ese rol preasignado. De modo tal que el comportamiento termina correspondiendo al estigma, autorrealizando la profecía.

No debe comprenderse la propuesta de Tonkonoff (2003) y Becker (2009) como un determinismo, se las entiende como posibilidades que pueden darse en las trayectorias juveniles. En términos de Goffman (1963), podríamos aducir que hablamos del plan de acción que el individuo decide llevar por el estigma que carga.

La falta de reconocimiento hacia los jóvenes de sectores populares se despliega toda vez que suman "un cuerpo" al indicador de muertes y éstas son descriptas por los medios de comunicación como "un número". En este sentido, dirá Butler (2010, p. 44), se tiende a "producir versiones icónicas de unas poblaciones eminentemente dignas de ser lloradas y de otras cuya pérdida no constituye una pérdida como tal al no ser objeto de duelo", como la vida de ciertos jóvenes, es decir, una expresión radical de menosprecio de determinadas trayectorias estigmatizadas. 
Para Honneth (1997), la ausencia, la falta, el mal o fallido reconocimiento provoca un daño en la subjetividad de los sujetos. Quienes sufren menosprecio o denegación del reconocimiento padecen situaciones de injusticia, lo que restringe negativamente su libertad de acción.

En las entrevistas con los jóvenes se advierten dificultades para sostenerse en el espacio público sin que su tránsito se vea mitigado por las fuerzas de seguridad. Sus trayectorias laborales y escolares se encuentran, de igual modo, atravesadas por la negación. Es decir, la experiencia de reconocimiento intersubjetivo se ve lesionado. El menosprecio que atraviesa la mirada policial y social sobre los jóvenes se traduce en un reconocimiento negativo que solo sirve para demorarlos, hostigarlos y detenerlos.

Para Honneth (1997), los sujetos definen su identidad en las relaciones intersubjetivas que se traman en los ámbitos de la familia, la sociedad y el Estado. Necesariamente, ese proceso de carácter dinámico y recíproco supone el conocimiento de otro interlocutor; operación que, recuperando a Hegel, el autor llama "reconocimiento". De acuerdo con Honneth (1997), la identidad se liga a actos de reconocimiento de otros sujetos y a las experiencias que devienen de su interacción en los ámbitos mencionados. A cada uno de ellos le corresponde una forma de reconocimiento: el amor en la familia, el derecho en la sociedad y la solidaridad en el Estado. En los mismos espacios pueden darse situaciones de exclusión, modos de menosprecio o humillación que atentan contra la autonomía, el autorrespeto y la autorrealización del sujeto.

Los jóvenes de sectores populares no presentan una libre disposición de sus cuerpos. El maltrato físico o corporal, considerado por el autor como la primera forma de menosprecio de tipo práctico, está presente en sus trayectorias vitales, sobre todo en las detenciones policiales. Señala el autor que, en lo específico, las formas de lesión física, como son los casos de violencia o tortura, tal como ocurren a los jóvenes entrevistados, no se encuentran constituidas por el dolor corporal, sino por su asociación con la 
posición indefensa del sujeto frente a la voluntad de "otro" (Honneth, 1997). En las experiencias de detención policial los jóvenes identifican diversas formas de tortura que lesionan su cuerpo:

Una vuelta me pegaron en el hígado, en el hígado, yo había empezado a vomitar, todo. (Champi, comunicación personal, 10 de enero de 2017)

Saben dónde pegar sin dejar marcas. (Lautaro, comunicación personal, 18 de mayo de 2016)

En el marco de demoras policiales, los jóvenes entrevistados acuerdan que las prácticas más violentas las representan el barquito y la mojarrita. La primera supone unir manos y pies a través de la espalda; la segunda, sumergir la cabeza forzadamente en el agua. Ambas son utilizadas como "método de indagación" policial. Asimismo, la superioridad del policía imprime en su accionar otras ofensas físicas, como el desnudo del cuerpo, tal como detalla Huapí en una experiencia de detención. Estas prácticas suponen menosprecio por parte de las fuerzas de seguridad y activan posteriormente el rechazo hacia la institución desde los afectados. Todas esas prácticas vulneran la autoconfianza en los términos que lo propone Honneth (1997). Una posición indefensa del sujeto frente a un otro que en estos casos está representado por los agentes de seguridad.

Los jóvenes detenidos, demorados y perseguidos por la policía, resultan privados de ciertos derechos que le corresponderían por ser miembros de una sociedad en la que participan igualitariamente en su ordenamiento institucional (Honneth, 1997). Esta segunda forma de menosprecio da como resultado sujetos excluidos socialmente. Lo específico de esta forma de menosprecio no se basa solo en la limitación de la autonomía personal, en tanto joven-ciudadano, sino en el sentimiento que asiste a un sujeto por encontrarse en condiciones diferentes de estatus. Por ello, esta experiencia de desposesión de derechos trae aparejada la pérdida de respeto de sí. 
Una vez, hace aproximadamente 8 años, venía del río de festejar el día del estudiante y pasamos por una colchonería (...) En la vereda había una cuna con un colchón que tenía un cigarrillo prendido (...) Por hacer un acto de bien, lo saqué de ahí y el dueño me vio desde adentro. Me fue a buscar y me dijo que ya había llamado a la policía, que llegó a los 5 minutos. Creyendo que había sido yo el que había tirado el pucho en el colchón, se lo hizo saber a uno de los policías. En el momento que me estaban tomando los datos, en plena calle, pasaba un montón de gente conocida y miraba la situación. Eso es la vergüenza, para mí (...) la pérdida de dignidad ante algo que hacemos. (Raiquen, comunicación personal, 5 de enero de 2017)

En la situación descripta por Raiquen hay una experiencia de negación de derechos constitucionalmente consagrados y tratamiento diferencial conforme al estatus social (Honneth, 1997). Una experiencia de discriminación y de violación del autorrespeto. Una comprensión de la vergüenza en tanto afectación por la pérdida de dignidad marcada por la mirada de los demás.

Raiquen habla sobre la falta de igualdad de oportunidades y del goce cultural: mientras que las posibilidades para algunos les son habilitadas, para otros se ven vedadas. Por su parte, Huapi toma los anteojos del racismo para mirar la discriminación. Entendiendo que en el horizonte hay una imposibilidad absoluta de que "cada uno haga la suya", lo cual no es más que despojarse de valoraciones que prefiguren sentidos y terminen por marcar el déficit ajeno. El joven habla de equidad de culturas, contra la segregación sistemática que habilita la jerarquización de valores y pérdida de autoestima.

\section{Consideraciones finales}

En esta instancia del trabajo interesa retomar el significado de la MdG, que no supone reconstruir una noción descriptiva y restrictiva, sino con valor político, porque la Marcha interviene 
en el debate público y construye agenda. La MdG es un fenómeno múltiple y en esa diversidad que aloja y que la constituye, radica su potencialidad. Su mutación a lo largo de los años permite realizar lecturas contextuales, dando cuenta de cómo se han sostenido y, a la vez, profundizado políticas públicas y lógicas de violencia institucional y estatal. Al mismo tiempo, su estudio historizado habilita reconstruir procesos de lucha colectiva y la progresiva constitución de MdG como movimiento social, extendiéndose cada vez más a otras ciudades y provincias del país.

Marcha de la Gorra para mí hoy es una bandera, o sea es la gran bandera que tenemos los movimientos sociales en la provincia de Córdoba (...) vos trabajás con jóvenes en situación de no acceso a tierra y a vivienda y tenés que ir con tu bandera a Marcha de la Gorra, porque ahí es donde están confluyendo masivamente las problemáticas sociales, porque aparte el mismo joven que cuando va a laburar al centro la policía lo detiene es el que después vuelve al barrio y no tiene dónde irse a vivir. (Deadpool, comunicación personal, 17 de julio de 2017)

El artículo tuvo como objetivo explorar una de las dimensiones relacionadas a la MdG: los procesos de estigmatización y falta de reconocimiento en jóvenes de sectores populares de las ciudades de Río Cuarto y Córdoba (Argentina), entendiendo dichos procesos como bases de las denuncia de la movilización. En ese sentido, pretendió mostrar otros aspectos asociados con la violencia institucional, dado que en esta oportunidad el eje no se encuentra en las acciones concretas desarrolladas por las fuerzas de seguridad, caracterizadas por la vulneración de (múltiples) derechos, sino en las experiencias individuales y personales de quienes la sufren, y los daños y efectos que la misma genera en las subjetividades de esos jóvenes, como así también en otras experiencias de menosprecio de su cotidianeidad.

A través de las palabras y sentires de los protagonistas fue posible acceder a una dimensión otra de la violencia institucio- 
nal, que termina constituyendo y justificando, por una parte, los procesos de estigmatización. Sobre ellos es posible identificar las diferentes maneras en que los jóvenes lidian individualmente con los estigmas que se les atribuyen: las confirmaciones con base en sus características físicas y culturales, que les reafirman sus sentires de encontrarse "afuera"; la asunción del mismo de forma positiva, que le permite posicionarse socialmente; la negación del estigma, separándose de las características atribuidas.

Por otra parte, respecto de la falta de reconocimiento, los análisis de Honneth (1997) habilitan profundizar en los efectos personales que ésta tiene para cada joven, pudiendo entender que no solo afecta a nivel del cuerpo el golpe recibido, sino también que la violencia es una vulneración de sus derechos, y conlleva una desvalorización de formas de vida.

Sin embargo, lo que interesa rescatar en esta comunicación es que dichas experiencias violentas son también motor que potencia la participación y la(s) lucha(s) contra esta violencia institucional que, como hemos podido entender, implica una construcción de una realidad y una manera de habitarla. Eso mismo es Marcha de la Gorra.

El documento de la $12^{\circ}$ edición, en la ciudad de Córdoba, comienza: "Hace 12 años tuvimos que inventar un día para poder vivir nuestras vidas y habitar las calles. Un día para que nuestros gustos, música, cultura e identidad ocupen el centro". La Marcha reconoce el estigma atribuido, se lo apropia y lo resignifica, haciendo del mismo su marca y su bandera.

Somos lxs vigiladxs, lxs perseguidxs, lxs verdugeadxs, lxs encarceladxs, lxs asesinadxs por el aparato del Estado. Somos consideradxs "peligrosxs" por quienes señalan los serruchos de los mapuches mientras ocultan las armas de la Gendarmería. Somos lxs que denuncian la represión a todos los pueblos originarios. Somos lxs villerxs, 1xs artesanxs, 1xs negrxs, 1xs trabajadorxs que enfrentamos la reforma laboral y la burocracia. Somos 
lxs que ocupamos tierras, lxs carrerxs, lxs militantes políticxs y sociales, lxs piqueterxs, lxs cuarteterxs, las trabajadoras sexuales, lxs trabajadorxs de la economía popular. Somos lxs cuerpxs sexogenéricamente disidentes y las mujeres que luchamos contra el patriarcado construyendo los feminismos, las que abortamos. Somos los medios alternativos, comunitarios y populares. (...) Somos la decimoprimera Marcha de la Gorra. (Fragmento del documento público de la decimoprimera Marcha de la Gorra)

No solo retoma las construcciones sobre los jóvenes - y diferentes sectores de la sociedad- para disputar sentidos. La MdG es una manifestación colectiva que entiende que la sumatoria de esas experiencias únicas, personales, pueden transformarse y transformar la realidad que los construye como "peligrosos" o "indeseables".

Este es nuestro momento histórico y tenemos claro que es necesario seguir construyendo formas alternativas a este sistema de muerte. Nuestra experiencia nos mostró que la organización y la lucha son las que nos permiten defender y conquistar más derechos. Hoy volvemos a demostrar que no sólo nos embroncamos: profundizamos la lucha con la convicción de que la salida es colectiva. La Marcha de la Gorra es una invitación a la resistencia, para todxs lxs oprimidxs, es una forma de visibilizar nuestras vidas, una expresión de la liberación de lxs cuerpxs a la vía pública. (Fragmento del documento público de la decimoprimera Marcha de la Gorra)

En estas palabras puede reconocerse que lo que se encuentra es una reivindicación de la diversidad en las formas de existencia, y en la denuncia explícita de un sistema de muerte y violencias. "Nosotres somos les de al lado. Terrorista es el Estado" (Fragmento del documento público de la decimosegunda Marcha de la Gorra). 
De esta manera, estudiar la MdG permite acercarse un poco más a la comprensión del sistema del que somos parte; habilita profundizar en diferentes dimensiones de la violencia institucional y sus formas de atravesar las subjetividades. Dicho reconocimiento suma en términos de poder modificar esas violencias. También, brinda luz sobre los procesos de construcción de otras formas de habitar (ésta) realidad, y de la constitución de una lucha que, como tantas otras, consolida como un paso hacia el logro de derechos y de una sociedad inclusiva y diversa.

Ahora bien al iniciar el texto nos preguntábamos: “¿cómo se ha desarrollado en Argentina la militancia en favor de los derechos humanos? ¿Cuál es el legado y su articulación con las organizaciones contra la violencia policial? ¿Cuáles son las banderas que portan? ¿Quiénes habitan hoy esos espacios?". Estas preguntas cobran sentido toda vez que aceptemos que la violencia institucional resulta una nominación construida desde el regreso de la democracia en Argentina, como resultado del diálogo entre organizaciones y activistas en favor de los derechos humanos, académicos y expertos. Una construcción teórico-política cuya apuesta ha sido nombrar, pero sobre todo hacer incidir, en la agenda pública temáticas vinculadas a un tipo particular de violencia, nombrada en principio como "violencia institucional". Entendemos que la Marcha de la Gorra es tributaria de esta militancia a favor de los derechos humanos, articulada contra la violencia policial. El espacio de la Marcha de la Gorra es habitado sobre todo por jóvenes que, basándose en las banderas de los derechos humanos, se proclamaron inicialmente contra la estigmatización y la falta de reconocimiento de los sectores populares.

Como quedó detallado en este artículo, hoy las demandas de la Marcha se amplían, lo cual nos invita a continuar problematizando las conjeturas, siempre provisorias, acerca de las violencias y sus marcas en las subjetividades de los jóvenes, y de los procesos de organización juvenil, contestatarios de los modos propios de la política tradicional, espacios que se cons- 
tituyen en sí mismos en escenarios de socialización y subjetivación juvenil.

\section{Referencias}

Alvarado S. V., Borelli S. y Vommaro P. (2010). Jóvenes, políticas y culturas: experiencias, acercamientos y diversidades. Buenos Aires: Homo Sapiens Ediciones.

Becker, H. (2009). Outsiders. Hacia una sociología de la desviación. Buenos Aires: Siglo XXI.

Benedicto, J. (1995). La construcción e los universos políticos de los ciudadanos. Sociología y Política. Temas de Sociología Política, 227-267.

Bonvillani, A. (Ed.). (2015). Callejeando la alegría... y también el bajón. Etnografía colectiva de la Marcha de la Gorra. Córdoba: Encuentro Grupo Editor.

Butler, J. (2010). Marcos de Guerra: las vidas lloradas. Barcelona: Paidós.

Calderón, F. (2011). Movimientos culturales y la emergencia de una nueva politicidad. Política y Sociedade, 10(18), 75-96.

Castel, R. (2013). La inseguridad social ¿Qué es estar protegido? Buenos Aires: Manantial.

Centro de Estudios Legales y Sociales. (1993). Violencia Institucional y Urbana. Buenos Aires: CELS.

Centro de Estudios Legales y Sociales. (2000). Violencia Institucional y Seguridad Ciudadana. Buenos Aires: CELS.

Chaboux, A. y Monsó, M. (Diciembre, 2015). Cartografiando devenires. Análisis etnográfico de la Marcha de la Gorra cómo espacio de acción política juvenil. En A. Oberti (Presidencia), Coordenadas contemporáneas de la sociología: tiempos, cuerpos, saberes. Jornadas llevadas a cabo en las XI Jornadas de Sociología de la Universidad de Buenos Aires, Argentina.

Chaves, M. (2005). Juventud negada y negativizada: Representaciones $\mathrm{y}$ formaciones discursivas vigentes en la Argentina contemporánea. Última Década, (23), 9-32.

Comisión Provincial de la Memoria de la Provincia de Buenos Aires. (2012). Notas para el debate. Recuperado de http://blog.comisionporlamemoria.org/wp-content/uploads/2012/12/ 
Documento_final_red.pdf

Cozzi, E. (2016). De juntas, clanes y broncas: Regulaciones de la violencia altamente lesiva entre jóvenes de sectores populares en dos barrios de la ciudad de Santa Fe. Delito y Sociedad, 39(24), 72-102.

Crisafulli, L. y León Barreto, I. (2015). Ritos y violencia en Córdoba. Los jóvenes y el estado penal. En M. Barrón y G. Borioli (Coomp.), Jóvenes cordobeses: de los márgenes al empoderamiento. Reflexiones sobre política (públicas). Córdoba: SeCyTFFyH, UNC.

Dahlgren, P. (2011). Jóvenes y participación política: los medios en la Red y la cultura cívica. Telos: Cuadernos de comunicación e innovación, (89), 12-22.

Daroqui, A. y López, A. (2012). La cadena punitiva: actores, discursos y prácticas enlazadas. En A. Daroqui, A. L. López y R. Cipriano (Coords), Sujetos de castigos. Hacia una sociología de la penalidad juvenil. Rosario: Homo Sapiens Ediciones.

Elias, N. (2003). Ensayo acerca de las relaciones entre establecidos y forasteros. Reis, 104, 219-255.

Gabrieloni, M. y Bonvillani, A. (2015). Luchar desde la alegría: la politicidad en las prácticas murgueras. En A. Bonvillani (Ed.), Callejeando la alegría... y también el bajón. Etnografía colectiva de la Marcha de la Gorra (pp. 151-176). Córdoba: Encuentro Grupo Editor.

Glaser, B. y Strauss, A. (1967). The discovery of grounded theory: Strategies for qualitative research. Nueva York: Aldine Publishing Company.

Goffman, E. (1963). Estigma. La identidad deteriorada. Buenos Aires: Amorrortu.

Guber, R. (2011). La etnografía. Método, campo y reflexividad. Buenos Aires: Siglo XXI Editores.

Guemureman, S. (2015). Adentro y afuera. Juventudes, sistema penal y políticas de seguridad. Buenos Aires: Grupo Editor Universitario.

Guemureman, S. y Gugliotta, A. (1998). Aportes para la reflexión acerca de la violencia perpetrada sobre los niños, niñas y adolescentes. En I. Izaguirre (Ed.), Violencia Social y Derechos Humanos. Buenos Aires: Eudeba.

Guemureman, S., Otamendi, A., Zajac, J., Sander, J. y Bianchi, E. (2017). 
Violencias y Violencias estatales: hacia un ejercicio de conceptualización. Revista Ensambles primavera, 4(7), 12-25.

Hall, S. (2010). El trabajo de la representación. En E. Restrepo, C. Walsh y V. Vich (Eds.), Sin garantías: Trayectorias y problemáticas en estudios culturales. Cali: Pontificia Universidad Javeriana y Universidad Andina Simón Bolívar.

Honneth, A. (1997). La lucha por el reconocimiento: por una gramática moral de los conflictos sociales. Barcelona: Crítica.

INDEC. (2015). Encuesta Nacional de Jóvenes 2014. Principales resultados. Recuperado de http://www.indec.gov.ar/ftp/cuadros/ poblacion/resultados_enj_2014.pdf

Juliano, M. y Etchichury, H. (2009). Código de faltas de la provincia de Córdoba. Ley 8431 y modificatorias comentado. Córdoba: Lerner.

Kornblit, A., Camarotti, A. y Di Leo, P. (2014). Brindemos con salud. La prevención en la escuela del consumo abusivo de alcohol. Buenos Aires: Novedades Educativas.

Le Breton, D. (2010). Rostros. Ensayo de antropología. Buenos Aires: Letra Viva.

Lerchundi, M. (2015). Comprensiones de juventud(es) y políticas públicas. Algunos abordajes posibles. Sociedad, Actores y Conocimiento: contribuciones desde la diversidad, 8, 201-218.

Lerchundi, M. (2016). ¿Jóvenes sujetos de derechos o... sin derechos? Cambios en el sistema contravencional (Córdoba, Argentina). Revista Latinoamericana de Derechos Humanos, 27(2), 159-172.

Llobet, V. (2015). Políticas y violencias en clave generacional en Argentina. En: J. M. Valenzuela Arce (Coord.), Juvenicidio. Ayotzinapa y las vidas precarias en América Latina y España (pp. 215235). México D.F.: Ned.

Merlino, A. (2012). Investigación Cualitativa y Análisis del Discurso. Argumentación, sistemas de creencias y generación de tipologías en el estudio de la producción discursiva. Buenos Aires: Editorial Biblos.

Míguez, D. y Semán, P. (2006). Entre santos, cumbias y piquetes: las culturas populares en la Argentina reciente. Buenos Aires: Editorial Biblios.

Pita, M. (2010). Formas de morir y formas de vivir el activismo contra la violencia policial. Buenos Aires: Del Puerto y CELS. 
Pita, M. (2017). Pensar la violencia institucional. Vox populi y categoría política local. Espacios de crítica y producción, 53, 25-32.

Reguillo, R. (2012). Emergencia de culturas juveniles. Estrategias del desencanto. Bogotá: Norma.

Rodríguez Alzueta, E. (2014). Temor y control. La gestión de la inseguridad como forma de gobierno. Buenos Aires: Futuro Anterior.

Roldán, M., Alonso, M. R. y Farías-Iten, D. P. (2015). La “Marcha de la Gorra" como experiencia de subjetivación política: explorando la noción de dispositivo al interior de la acción colectiva juvenil. En C. Mera (Presidencia), VIII Jornadas de Jóvenes Investigadores Instituto de Investigaciones Gino Germani. Jornadas en el Instituto de Investigaciones Gino Germani, Facultad de Ciencias Sociales de la Universidad de Buenos Aires, Argentina.

Roldán, M., Alonso, M. R. y Farías-Iten, P. D. (2016). Procesos de subjetivación política en la acción colectiva juvenil. Jangwa Pana, 15(2), 165.

Segato, R. (2006). Racismo, discriminación y acciones afirmativas: herramientas conceptuales. Série Antropologia, 404, 1-19.

Shuster, F., Pérez, G., Pereyra, S., Armesto, M., Armelino, M., García, A., Natalucci, A., Vázquez, M. y Zipcioglu, P. (2006). Transformaciones de la protesta social en Argentina 1989-2003. Buenos Aires: Instituto de Investigaciones Gino Germani, Facultad de Ciencias Sociales, Universidad de Buenos Aires.

Tarrow, S. (1997). El poder en movimiento. Los movimientos sociales, la acción colectiva y la política. Madrid: Alianza.

Taylor, S. y Bodgan, R. (1990). Introducción a los métodos cualitativos en investigación. La búsqueda de los significados. Barcelona: Paidós.

Tiscornia, S. (2017). La violencia institucional como tema de trabajo e investigación. Una breve historia. Espacios de Crítica y Producción, 53, 25-32.

Tonkonoff, S. (2003). Microdelitos, juventudes y violencias: La balada de los Pibes Chorros. Delito y Sociedad, 12(18/19), 109-125.

Vommaro, P. y Vázquez, M. (2008). La participación juvenil en los movimientos sociales autónomos de la Argentina: El caso de los Movimientos de Trabajadores Desocupados (MTDs). Revista Latinoamericana de Ciencias Sociales, Niñez y Juventud, 6(2), 485-522. 
Violencia institucional y participacion política juvenil: la experiencia de la Marcha de la Gorra (Córdoba) - Lerchundi y Alonso

Vommaro, P. (2015). Juventudes y políticas en la Argentina y en América Latina. Buenos Aires: Grupo Universitario Editor.

Wacquant, L. (2004). Las cárceles de la miseria. Buenos Aires: Manantial. 